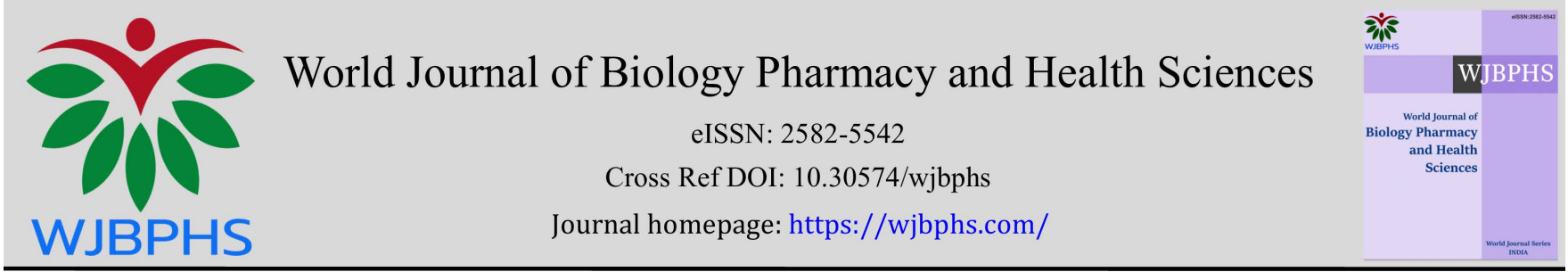

(RESEARCH ARTiCLE)

\title{
Biofertilizer based on liquid fermented with Inula viscosa, microorganisms and algae in the growth and biocontrol of Sphaerotheca pannosa var. rosae of seed rose plants
}

\author{
Domenico Prisa * \\ CREA Research Centre for Vegetable and Ornamental Crops, Council for Agricultural Research and Economics, Via dei \\ Fiori 8, 51012 Pescia, PT, Italy.
}

World Journal of Biology Pharmacy and Health Sciences, 2021, 06(03), 020-026

Publication history: Received on 19 May 2021; revised on 20 June 2021; accepted on 23 June

2021 Article DOI: https://doi.org/10.30574/wjbphs.2021.6.3.0042

\begin{abstract}
Research goal: Based on the information obtained from the literature on Inula viscosa, in particular on the insecticidal and antifungal capacities of this plant, the aim of this work was to carry out further experiments on a macerate based on Inula viscosa, microorganisms and algae in order to evaluate the bio stimulant and biocontrol capacities on rose plants obtained from seed.
\end{abstract}

Materials and Methods: The experiments, which started in January 2021, were conducted in the greenhouses of CREAOF in Pescia (Pt). The experiment was divided into two parts. A seed germination test and a plant growth test, both conducted during the same experiment. The four experimental groups in cultivation were: i) group without biofertilizer, irrigated with water and previously fertilized substrate; ii) group with Inula biofertilizer, microorganisms and algae (INORT); iii) group with algae (Ascophyllum nodosum extract); iv) group with beneficial bacteria.

Results and Discussion: The test showed a significant increase in the agronomic parameters analysed in plants treated with the INORT biofertilizer on seed roses. The test also showed greater control of the pathogen Sphaerotheca pannosa var. rosae in seedlings sprayed with the biofertilizer. In fact, all plants treated with INORT showed a significant increase in the height and number of leaves per plant, in the vegetative and root weight of the plants, in the number and duration of flowers, a reduction in the attack of the pathogen Sphaerotheca pannosa var. rosae, an increase in seed germination and a reduction in the average germination time.

Conclusions: The experiment at CREA-OF in Pescia has therefore demonstrated how the application of a macerate based on Inula viscosa, microorganisms and algae can significantly improve the cultivation and quality of seed rose plants. As in other experiments, the application of this biostimulant also determined positive effects in the control of pathogenic fungi, in particular Sphaerotheca pannosa var. rosae. Other investigations are currently underway to study the biostimulant and desiccant capacities of the Inula plant, depending on the harvesting methods, the physiological state of the plants, the extraction method, the type of culture medium, the type and timing of maceration. The association with various microbial consortia and other plant-derived biostimulants will also be evaluated.

Keywords: Biofertilizers; Sustainable agriculture; Ornamental plants; Organic farming; Pest control

\section{Introduction}

Inula viscosa (Compositae) is a perennial weed native to the Mediterranean basin. It has sticky (viscous) leaves with an aromatic odour. It is generally not attacked by parasites and there are no animals that feed on it. In phytotherapy the

\footnotetext{
${ }^{*}$ Corresponding author: Domenico Prisa

CREA Research Centre for Vegetable and Ornamental Crops, Council for Agricultural Research and Economics, Via dei Fiori 8, 51012 Pescia, PT, Italy.
}

Copyright (C) 2021 Author(s) retain the copyright of this article. This article is published under the terms of the Creative Commons Attribution Liscense 4.0. 
extracts are used for inflammations and the dry shoots to repel insects. Chemical analysis of the plant tissues of $I$. viscosa has revealed the presence of a number of terpenoid compounds, which show antifungal activity. The flowers are characterised by a modified disc-shaped receptacle, differentiated into tubular (usually in the centre) [1]. Generally, the flowers are pollinated by bees, they produce fruits called achenes, which may or may not have a pappus (bristle-like appendage), which allows dispersal by the wind. It prefers calcareous and clayey soils, often acidic, and is found between 0 and $800 \mathrm{~m}$ altitude. Because of its spread, it is considered a weed and for many years now there have been many scientific studies that have reassessed its potential [2,3]. Inula is an important plant for insects, as it has a high melliferous power, is characterised by a very long flowering period and therefore represents an important source of food for insects $[4,5]$.

The flowers are characterised by a modified disc-shaped receptacle, differentiated into tubular (usually in the centre). Generally, the flowers are pollinated by bees, they produce fruits called achenes, which may or may not have a pappus (bristle-like appendage), which allows dispersal by the wind. It prefers calcareous and clayey soils, often acidic, and is found between 0 and $800 \mathrm{~m}$ altitude. Because of its spread, it is considered a weed and for many years now there have been many scientific studies that have reassessed its potential [6]. Inula is an important plant for insects, as it has a high melliferous power, is characterised by a very long flowering period and therefore represents an important source of food for insects [7]. Inula viscosa is nowadays a much-studied plant from an agronomic point of view (the components of the extracts are evaluated as anti-germinants, desiccants and for the biological control of insects and fungi) or for the preparation of medicines. Easily cultivated, with a long growth phase, it is adaptable to hostile and arid environments $[8]$.

In some Mediterranean agroecosystems, it is used for crop pest control, as it has a high potential to retain and increase the presence of predators. Its ability to attract and feed caterpillars of predatory insects and its tolerance to environmental stresses are decisive factors that make it potentially suitable for biological control in the Mediterranean region [4].

Leaf extracts of I. viscosa have fungicidal, nematicidal and antibacterial activities [9,10]. This plant also represents a source of bioactive ingredients with significant acaricidal activity that could lead to the development of new and safe bio-acaricides [11]. With regard to fungal control, preparations based on I. viscose preparations provide control of pathogens belonging to the Oomycetes, Ascomycetes, and Basidiomycetes families [12]. Interesting effects were also found in the control of downy mildew, in particular tomentosine and costic acid, which also showed excellent activity against the disease in the field [13].

Based on the information obtained from the literature on Inula viscosa (Figure 1), in particular on the insecticidal and antifungal capacities of this plant, the aim of this work was to carry out further experiments on a macerate based on Inula viscosa, microorganisms and algae in order to evaluate the biostimulant and biocontrol capacity in the cultivation and defence of rose plants obtained from seeds.

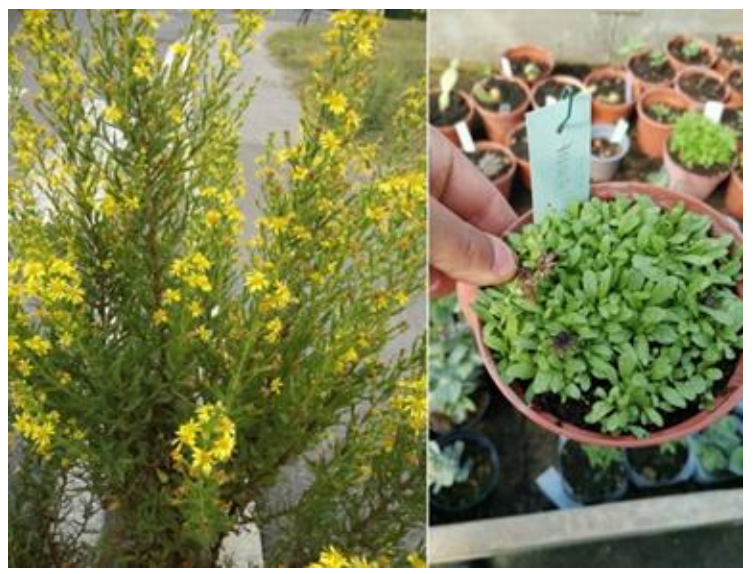

Figure 1- Detail of the Inula plant in the field and germinated seedlings in the nursery in the greenhouses of CREA-OF in Pescia 


\section{Material and methods}

\subsection{Greenhouse experiment and growing conditions}

The experiments, started in January 2021, were conducted in the greenhouses of CREA-OF in Pescia (Pt), Tuscany, Italy $\left(43^{\circ} 54^{\prime} \mathrm{N} 10^{\circ} 41^{\prime} \mathrm{E}\right)$ on roses grown from seed (Figure 2$)$. The experiment was divided into two parts. A seed germination and a plant growth trials, both carried out during the same experiment.

\subsubsection{Germination test}

In the germination test, the seeds were placed in $\varnothing 12 \mathrm{~cm}$ pots, in potting soil for sowing (blond peat $40 \%$, Black peat $60 \%$, silica sand $80 \mathrm{l} / \mathrm{m}^{3}$, fertilization $500 / \mathrm{m}^{3} \mathrm{NPK}, \mathrm{pH} 5.7$ ); 200 seeds per thesis, divided into 4 replicas of 50 seeds each.

The four experimental groups in cultivation were:

- Group without biofertilizers (CTRL), irrigated with water and substrate previously fertilized;

- Group with Inula biofertilizers (INORT): (mix Microorganisms + Inula viscosa + Algae), irrigated with water and substrate previously fertilized. Irrigation treatment with $(10 \mathrm{ml}$ per pot $)$ once per week. The product INORT was supplied by the Francesco Attanasio farm;

- Group with algae (AG): (Ascophyllum nodosum extract, Grow spira, Richa biotech), irrigated with water and substrate previously fertilized. Irrigation treatment with (10 ml per pot) once per week;

- $\quad$ group with beneficial bacteria (BAC): (TNC Bactorrs13): Bacillus amyloliquefaciens, B. brevis, B. cirulans, B. coagulans, B. firmus, B. halodenitrificans, B. laterosporus, B. licheniformis, B. megaterium, B. mycoides, B. pasteuri, B. polymyxa, B. Subtilis $\left(1.3 \times 10^{11} \mathrm{cfu} / \mathrm{kg}\right)$; Mix $1.5 \mathrm{~g}$ (approx $\left.1 / 2 \mathrm{tsp}\right)$ with every litre of soil;

\subsubsection{Growth test}

In the rose cultivation test, 60 plants were taken from the control thesis of the germination test. Each thesis was characterized by 15 plants in $\emptyset 10 \mathrm{~cm}$ pots, divided into 3 replicates of 5 plants each. All plants were fertilized with a controlled release fertilizer ( $2 \mathrm{~kg} \mathrm{~m}^{-3}$ Osmocote Pro®, 9-12 months with $190 \mathrm{~g} / \mathrm{kg} \mathrm{N}, 39 \mathrm{~g} / \mathrm{kg} \mathrm{P,} 83 \mathrm{~g} / \mathrm{kg} \mathrm{K}$ ) mixed with the growing medium before transplanting. The experimental groups were:

The four experimental groups in cultivation were:

- Group without biofertilizers (CTRL): (peat 70\% + pumice 30\%), irrigated with water and substrate previously fertilized;

- Group with Inula biofertilizers (INORT): (mix Microorganisms + Inula viscosa + Algae): (peat 70\% + pumice $20 \%$ ), irrigated with water and substrate previously fertilized. Irrigation and spray treatment with (25 ml per plant) per week during the growing cycle;

- Group with algae (ALG): (Ascophyllum nodosum extract, Grow spira, Richa biotech), (peat 70\% + pumice 20\%), irrigated with water and substrate previously fertilized. Irrigation and spray treatment with (25 ml per plant) per week during the growing cycle;

- $\quad$ group with beneficial bacteria (BAC): (TNC Bactorrs13): Bacillus amyloliquefaciens, B. brevis, B. cirulans, B. coagulans, B. firmus, B. halodenitrificans, B. laterosporus, B. licheniformis, B. megaterium, B. mycoides, B. pasteuri, B. polymyxa, B. Subtilis $\left(1.3 \times 10^{11} \mathrm{cfu} / \mathrm{kg}\right)$; Mix $1.5 \mathrm{~g}$ (approx $\left.1 / 2 \mathrm{tsp}\right)$ with every litre of soil;

The plants were watered 2 times per days, 7 days a week and grown for 6 months. The plants were irrigated with drip irrigation. The irrigation was activated by a timer whose program was adjusted weekly according to climatic conditions and the fraction of leaching. On June 3,2021, seeds germination, average germination time, plants height, leaves number, vegetative and radical weight, flowers number, flowers life, were recorded. In addition, infection of the plants by powdery mildew (Sphaerotheca pannosa var. rosae) was assessed in the experiment. 

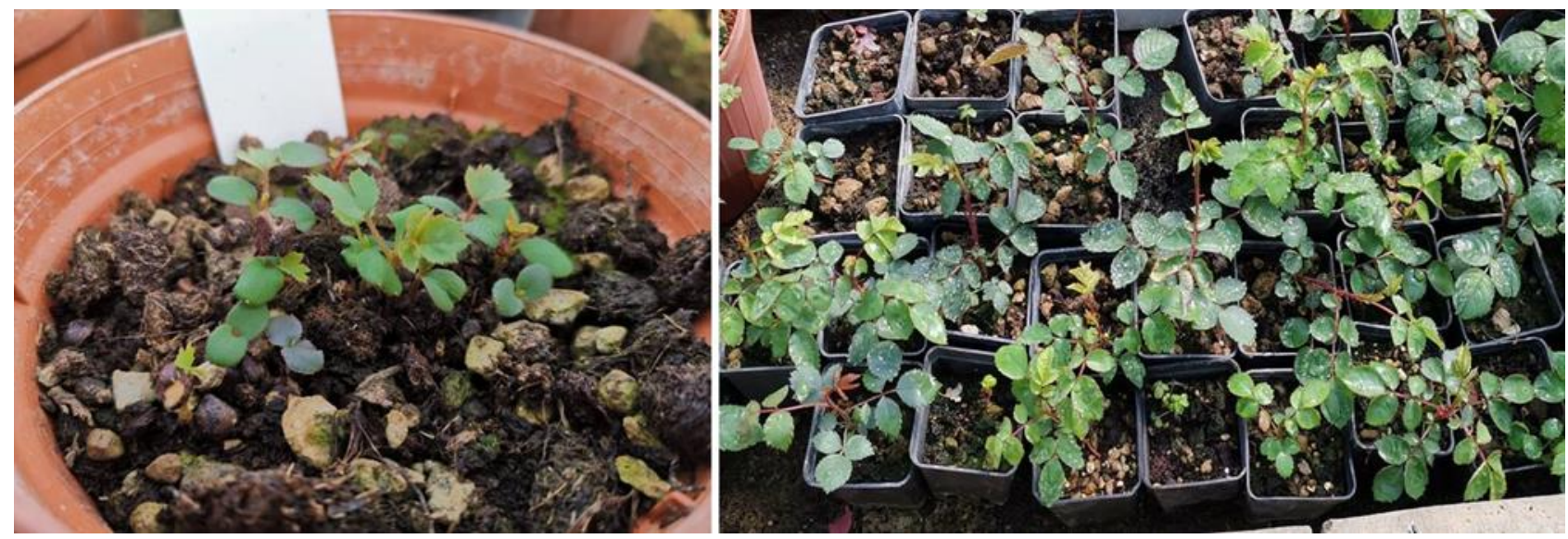

Figure 2 - Detail of rose plants from seed grown in the CREA-OF nursery in Pescia

\subsection{Statistics}

The experiment was carried out in a randomized complete block design. Collected data were analysed by one-way ANOVA, using GLM univariate procedure, to assess significant $(P \leq 0.05,0.01$ and 0.001$)$ differences among treatments. Mean values were then separated by LSD multiple-range test $(P=0.05)$. Statistics and graphics were supported by the programs Costat (version 6.451) and Excel (Office 2010).

\section{Results and discussion}

The test showed a significant increase in the agronomic parameters analysed in plants treated with the INORT biofertilizer on seed roses. The test also showed greater control of the pathogen Sphaerotheca pannosa var. rosae in seedlings sprayed with the same product than in the other theses evaluated.

There was also a significant improvement in the agronomic parameters tested with the other products used based on algae and microorganisms compared to the control, but with lower results than with the INORT biofertilizer. In fact, all plants treated with INORT showed a significant increase in the height and number of leaves per plant, the vegetative and root weight of the plants, the number and duration of flowers, a reduction in the attack by the pathogen Sphaerotheca pannosa var. rosae, an increase in seed germination and a reduction in average germination time.

Specifically, in (Table 1), it is shown that treatment (INORT) significantly improved plant height with $46.46 \mathrm{~cm}$, compared to $43.56 \mathrm{~cm}$ (ALG), $42.83 \mathrm{~cm}$ (BAC) and $40.64 \mathrm{~cm}$ (CTRL) (Figure 3). The use of Inula-based biofertilizer significantly increased the number of leaves per plant by 33.61 (INORT), 28.24 (ALG), 26.00 (BAC) and 23.44 (CTRL). It also increased the vegetative weight, $52.57 \mathrm{~g}$ (INORT), $48.36 \mathrm{~g}$ (ALG), $47.55 \mathrm{~g}$ (BAC) and $44.86 \mathrm{~g}$ of the untreated control and roots weight $40.43 \mathrm{~g}$ (INORT), $38.02 \mathrm{~g}$ (ALG), $37.10 \mathrm{~g}$ (BAC) and $34.60 \mathrm{~g}$ (CTRL) (Figure 4).

The test also showed a significant increase in the number of new flowers 13.81 (INORT), compared to 7.44 (ALG), 7.00 (BAC) and 5.86 in the control. In addition, there was a significant increase in flowering time in the fermented INULA thesis (INORT) 9.80 days, compared to 7.20 in (ALG), 6.80 in (BAC) and 6.20 in the control. The trial also showed that (INORT) can have a biocontrol effect on the pathogen Sphaerotheca pannosa var. rosae. In fact, in the theses sprayed with Inula fermentate, 0.20 plants were affected by the fungus, in (BAC) 1.00, in (ALG) 2.00 compared to the control where 3.40 plants were attacked. In relation to seed germination, the thesis (INORT) was the best with 44.20 germinated seeds, followed by (ALG) with 36.61, (BAC) with 34.64 and (CTRL) with 28.23. Regarding the mean germination time, (INORT) was also the best thesis with 24.00 days, (ALG) 30.40 days, (BAC) 31.20 days and the control with 33.60 (CTRL).

The results of this trial showed how the use of a biofertilizer based on Inula viscosa can improve the growth and defence of rose seed plants. In the literature there were some researches that shows that the use of Inula can inhibit the germination and development of some plants [14]. This effect is probably due to some of the secondary metabolites present in Inula, the method and time of preparation of the extract, the type of plant on which the fermented product is used, the growth stage and the quality of plant tissue of the plant from which the metabolites are taken. In this research as in others previously carried out on other vegetable and ornament plants $[2,7,15]$ the use of Inula macerate associated or not with other compounds of natural origin such as algae or microbial-based biofertilizers showed a significant improvement in the growth of the plants in experiment. Inula has also shown in several cases a effect in the control of 
certain seedling pathogens such as Pithyum spp. and Fusarium sp. [2,7] and in this trial control of the pathogen Sphaerotheca pannosa var. rosae.

Table 1 Evaluation of INORT on agronomic characters of seed roses

\begin{tabular}{|c|c|c|c|c|c|c|c|c|c|}
\hline Groups & $\mathrm{PH}(\mathrm{cm})$ & $\operatorname{LN}\left(n^{\circ}\right)$ & VW (g) & RW (g) & FN $\left(n^{\circ}\right)$ & FL (days) & $\operatorname{PI}\left(n^{\circ}\right)$ & $S G\left(n^{\circ}\right)$ & GT (days) \\
\hline CTRL & $40,64 \mathrm{c}$ & $23,44 \mathrm{c}$ & $44,86 \mathrm{c}$ & $34,60 \mathrm{~d}$ & $5,86 \mathrm{c}$ & $6,20 \mathrm{c}$ & $3,40 \mathrm{a}$ & $28,23 \mathrm{~d}$ & $33,60 \mathrm{a}$ \\
\hline INORT & $46,46 \mathrm{a}$ & $33,61 \mathrm{a}$ & $52,57 \mathrm{a}$ & $40,43 \mathrm{a}$ & $13,81 \mathrm{a}$ & $9,80 \mathrm{a}$ & $0,20 \mathrm{~b}$ & $44,20 \mathrm{a}$ & $24,00 \mathrm{c}$ \\
\hline ALG & $43,56 \mathrm{~b}$ & $28,24 \mathrm{~b}$ & $48,36 \mathrm{~b}$ & $38,02 \mathrm{~b}$ & $7,44 \mathrm{~b}$ & $7,20 \mathrm{~b}$ & $2,00 \mathrm{ab}$ & $36,61 \mathrm{~b}$ & $30,40 \mathrm{~b}$ \\
\hline BAC & $42,83 \mathrm{~b}$ & $26,00 \mathrm{~b}$ & $47,55 \mathrm{~b}$ & $37,10 \mathrm{c}$ & $7,00 \mathrm{~b}$ & $6,80 \mathrm{bc}$ & $1,00 \mathrm{~b}$ & $34,64 \mathrm{c}$ & $31,20 \mathrm{~b}$ \\
\hline ANOVA & $* * *$ & $* * *$ & $* * *$ & $* * *$ & $* * *$ & $* * *$ & $*$ & $* * *$ & $* * *$ \\
\hline
\end{tabular}

One-way ANOVA; n.s. - non significant; *,***** - significant at $\mathrm{P} \leq 0.05,0.01$ and 0.001 , respectively; different letters for the same element indicate significant differences according to Tukey's (HSD) multiple-range test ( $\mathrm{P}=0.05)$.Legend: (CTRL): control; (INORT): mix Inula, microorganisms and algae;(ALG): Ascophyllum nodosum; (BAC): TNC Bactorrs13 microorganisms; PH: plant height; LN: leaves number; VW: vegetative weight; RW: roots weight; FN: flowers number; FL: flowers life; PI: plants infected by Sphaerotheca pannosa var. rosae; SG: number of seeds germinated; GT: germination time

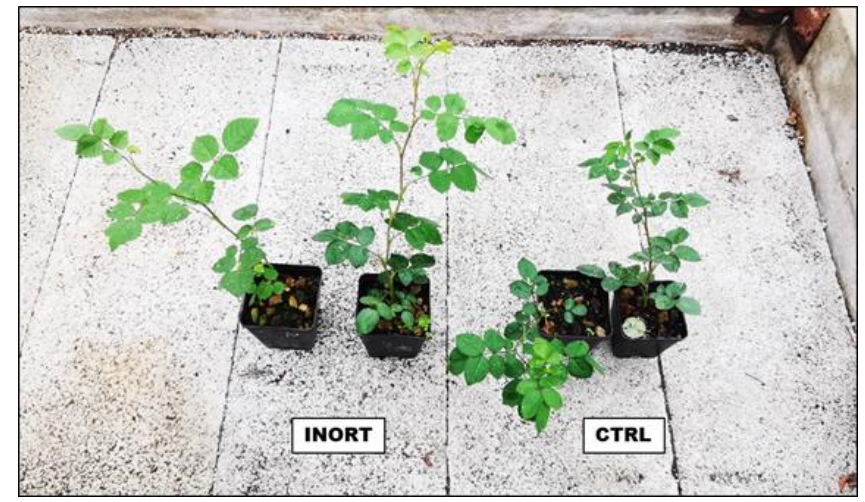

Figure 3- Effect of INORT on vegetative biomass of seed roses Legend: (CTRL) control; (INORT) mix Inula, microorganisms and algae

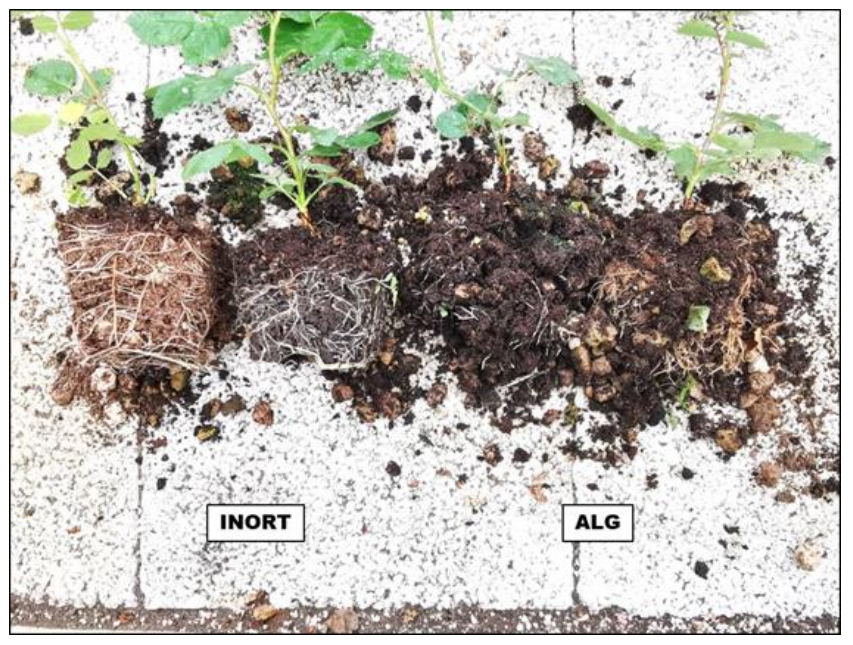

Figure 4 Effect of INORT on roots biomass of seed roses Legend: (INORT) mix Inula, microorganisms and algae; (ALG) Ascophyllum nodosum

This plant, as other trials have shown, not only plays an important role in agriculture, it can be used in the form of a macerate with a biostimulant or repellent action against certain pathogenic insects. It also plays a fundamental role for plant biodiversity, as it provides a possible refuge for plant antagonists of the olive fly such as Eupelmus urozonus, a 
polyphagous parasitoid of the Hymenoptera Chalcidoids, find refuge on it [16]. Further studies have been conducted to evaluate Inula in the control of varroa in bees, both by extracting of the costic acid, or by using the macerate in a gel to be sprayed in the hive, which gave numerous positive results $[17,18,19]$. Further studies on I. viscosa extracts have also showed antifungal activity for phytopathogenic fungi and secondary plant metabolites present in this plant are recognised for their insecticidal, acaricidal, antimicrobial and phytotoxic activity [20].

Further research will be carried out in the future to improve protocols for the use of Inula products, to assess whether bio stimulant effects are present on different types of plants, and to identify which phytopathogens the macerate has a biocontrol function on.

\section{Conclusion}

The trial at CREA-OF in Pescia showed how the application of a macerate based on Inula viscosa and microorganisms can significantly improve the cultivation and quality of seed rose plants. As in other experiments, the application of this biostimulant also determined positive effects in the control of pathogenic fungi, in particular Sphaerotheca pannosa var. rosae. This effect was probably caused by the tomentosine and costic acid present in the tissues of this plant. Interesting results were also the increase in seed germination, the reduction in average germination time and the prolongation of flower life in theses treated with the INORT product. Other investigations are currently in progress to investigate the biostimulant and desiccant capacities of Inula, depending on harvesting methods, physiological state of the plants, method of extraction, type of growing medium, kind and timing of maceration. The association with various microbial consortia and other plant-derived biostimulants will also be evaluated.

\section{Compliance with ethical standards}

\section{Acknowledgments}

The research is part of the project "INORT": evaluation of derivates of Inula viscosa in the growth and defense of horticultural plants. Special thanks to Francesco Attanasio for his cooperation in the implementation of the project.

\section{Disclosure of conflict of interest}

The author declares no conflict of interest.

\section{References}

[1] Bachir RG, Nour H. Antibacterial and antioxidant activites of essential oil of Inula viscosa L. from Northwes Algeria. Advances in Pharmacognosy and phytomedicine. 2015. 1(1): 10-16.

[2] Prisa D. Biostimulant based on Inula viscosa L. (Dittrichia viscosa L.), algae and microorganisms in the growth and defense of Spinacia oleracea L. and Lactuca sativa L.," International Journal of Scientific Research in Multidisciplinary Studies. 2020. 6(11): 1-6.

[3] Villani R. Inula viscosa: una pianta dalle molteplici proprietà, usi tradizionali e analisi preliminari. Tesi sperimentale in colture officinali, Università degli studi di Salerno. 2019-2020.

[4] Perdikis D, Favas C, Lykouressis D, Fantionou A. Ecological relationship between non-coltivated plants and insect predators in agroecosystems:the case oh Dittrichia viscosa( Asteraceae) and Macrolophus melanotoma (Hemiptera: Miridae). Acta Oecologica, Sciencedirect. 2007. 31(3): 299-306.

[5] Maoz M, Neeman I. Effect of Inula viscosa extract on chitin synthesis in dermatophytes and Candida albicans. J. Ethnopharmacol. 2000. 71: 479-482.

[6] Wang W, Ben-Daniel BH, Cohen Y. Control of plant diseases by extracts of Inula viscosa. Dis. Control Pest Manage. 2004. 94: 1042-1047.

[7] Prisa D. Possible use of Inula viscosa (Dittrichia viscosa L.) for biostimulation of Oscularia deltoides and Corpuscolaria lehmanii plants and protection against Aphis nerii. GSC Biological and Pharmaceutical Sciences. 2019. 9(3): 69- 75 .

[8] Al-Dissi NM, Salhab AS, Al-Hajj HA. Effects of Inula viscosa leaf extracts on abortion and implantation in rats. Journal of Ethnopharmacology. 2001. 77: 117-121. 
[9] Oka Y, Ben-Daniel BH, Cohen Y. Nematicidal activity of powder and extracts of Inula viscosa. Nematology. 2001. 3: 735-742.

[10] Maoz M, Kashman Y, Neeman I. Isolation and identification of a new antifungal sesquiterpene lactone from Inula viscosa. Planta Medica. 1999. 65: 281-282.

[11] Parolin P, M Ion Scotta, C Bresch. Biology of Dittrichia viscosa, a Mediterranean ruderal plant: a review, FYTON. 2014. 83: 251-262.

[12] Wang W, Ben-Daniel BH, Cohen Y. Control of plant diseases by extracts of Inula viscosa. Phytopathology. 2004. 94: 1042-1047.

[13] Cohen Y, Wang W, Ben-Daniel BH, Ben-Daniel Y. Extracts of Inula viscosa control downy mildew of grapes caused by Plasmopara viticola. Phytopathology. 2006. 96: 417-424.

[14] Celik TA, Aslantürk OS. Evaluation of cytotoxicity and genotoxicity of Inula viscosa leaf extracts with Allium test. Journal of Biomedicine and Biotechnology. 2010. 1-8.

[15] Prisa D. Improving Quality and Production of Horticultural Crops Through the Use of A Biostimulant Based on Inula Viscosa and Control of Seedling Pathogens. International Journal of Scientific Research in Research Paper. Biological Sciences. 2021. 8(1): 21-27.

[16] Prisa D. Inula: olive fly control and bee protection by varroa. Edizioni lulu. Book ISBN: 9780244752583. 2019; 79.

[17] Prisa D. Ritorno alle origini. Microrganismi EM, protocolli ed esperienze per un'apicoltura sostenibile. Apinsieme. 2016. 28-34.

[18] Prisa D. Apicoltura biologica metodi innovativi naturali e difesa delle api. (parte 1). 2017. 42-45.

[19] Prisa D. Apicoltura biologica metodi innovativi naturali e difesa delle api. (parte 2). 2017. 42-45.

[20] Mahmoudi H. Comprehensive phytochemical analysis, antioxidant and antifungal activities of Inula viscosa Aiton leaves. Jurnal of Food Safety. 2015. 36(1): 77-88. 